\title{
HABIT REVERSAL USED TO TREAT ONYCHOPHAGIA: A CASE REPORT
}

\author{
Georg Authried ${ }^{1}$; Mathias Tiedemann Svendsen ${ }^{2}$ \\ Correspondence: georg.authried@amstetten.lknoe.at \\ ${ }^{1}$ Landesklinikum Amstetten, Austria; ${ }^{2}$ Department of Dermatology and Allergy Centre, Odense University Hospital \& Institute of Clinical \\ Research, University of Southern Denmark, Odense, Denmark
}

\section{ABSTRACT}

Chronic nail biting (onychophagia) is a common habit which negatively impacts on the quality of life of those affected, has a negative social impact, and is accompanied with disabling inflammatory processes like gingivitis and paronychia. Habit reversal is a behaviour treatment procedure used to help patients get rid of the habit. The presented case report describes how a six-month period of habit reversal prescribed by the dermatologist was used to treat a 42-year male suffering from life-long onychophagia. During the treatment period, the patient experienced both an improved growth of nails and an improvement in quality of life, but never got fully cured from the habit. Finally, suggestions for an improved treatment success by prescribing habit reversal in specialized onychophagia clinics run by a multidisciplinary team (consisting of e.g., dermatologists, psychiatrists, and psychologists) who ensure regular follow-ups and patient compliance is provided.

Keywords: Onychophagia, habit reversal, quality of life.

\section{Article History:}

Received: July 7, 2021

Accepted: August 31, 2021

Published: September 30, 2021
Cite this as: Authried, G. Svendsen, M.T. Habit reversal used to treat onycophagia: a case report. Journal of Psychiatry Psychology and Behavioral Research; 2021.Vol. 2, Issue 2, p. 1-3.

\section{INTRODUCTION}

Chronic nail-biting or onychophagia is an underestimated habit which severely affects quality of life for those affected. Although most affected patients are aware they bite their nails, it can be challenging dropping the habit. ${ }^{1,2}$

Habit reversal, a behavioural procedure to treat nervous habits, is one of the treatment regimens available to help reducing onychophagia or at least to get aware of it and its warning signs. ${ }^{2}$ It is a multicomponent procedure used in the treatment of nervous habits and tics. It originally consisted of various treatment components and phases like awareness training, competing response training, motivation procedures and generalization procedures applied to achieve reductions in a targeted bothering habit. ${ }^{3}$ Later it was simplified, and the treatment components of awareness training and competing response practice were kept as the essential elements. However, social support as further component in habit reversal was retained as an important element mainly in the treatment of children. The purpose of habit reversal and especially awareness and competing response training is to impart the skills necessary to identify the occurrence of the habit and respond with an incompatible and harmless behaviour, while the purpose of social support is to provide the motivation to continue using the competing response procedure. ${ }^{3,4,5}$
Unfortunately, compliance to habit reversal may be low and the effect only temporary, as reported in this case report.

\section{CASE}

A 42-year-old, Caucasian male was referred from his general practitioner (GP) to the department of dermatology (DOD) for a second opinion of a nail disorder. He was known with severe onychophagia (diagnosed by his GP) as well as chronic depression and anxiety, the latter treated with paroxetine prescribed by a psychiatrist. He reported a habit of biting and manipulating the nails and cuticles. The habit was mainly related to boredom, frustration, and stress. The custom had started in primary school when the patient was around the age of six.

At the first visit at the dermatologist, the patient presented with uneven distal edges of the nail, traumatised cuticles, and a splinter haemorrhage within the nail plate of the right thumb (Fig. 1. A). The Dermatology Life Quality Index (DLQI) ${ }^{6}$ (a validated dermatology specific qualify of life (OQL) score with an interval from $0-30$, going from 0 (not affected) to 30 (severely affected)) was measured to 15 (due to affecting patients being embarrassed and insecure, affecting leisure activities and relationship to partner, family, and friends). 
Numerous previous attempts like plasters and bitter tasting nail enamel had been prescribed by the GP to reverse the biting behaviour. However, it had just hold him from biting the nails for a short time-period (weeks). There was a need for a longsighted treatment plan. He was introduced to habit reversal by the dermatologist: every time he felt the urge biting the nails, he should find an alternative habit like making a fist, sitting on his hands, or holding a pencil. ${ }^{2} \mathrm{He}$ was instructed to making a fist and beating it gently against the stomach, whenever he felt the urge manipulating and biting the nails and cuticles. In addition, he was advised to clip long fingernails instead of biting them. He was daily supervised by his wife and related to his regular visits at the DOD, where the DLQI was measured. The DLQI and the objective clinical improvement were considered as therapy targets.

The patient had a follow-up meeting at the DOD one month after habit reversal had been prescribed. Clinical improvement could already be noticed. The fingernails had gotten longer, and the skin had begun to heal (Fig. 1. B). DLQI had dropped to 6 (scores for affecting relationship to partner and for treatment being time-consuming). Nevertheless, in the following months, the patient experienced throwbacks, patient-reported compliance to practising habit reversal dropped, and he could not get fully rid of the habit. Despite, some clinical improvement was noticed at a follow-up visit four months after the first visit (Fig. 1. C). DLQI had slightly increased to 8 (scores for being embarrassed, affecting relationship to partner and for treatment being timeconsuming). Overall, he did not get rid of the habit biting nails long-term, as seen at the appointment six month after the first visit, where the nails still had a bitten appearance (Fig. 1. D). DLQI had further increased to 9 (maximum scores for being embarrassed, affecting relationship to partner, family, and friends).
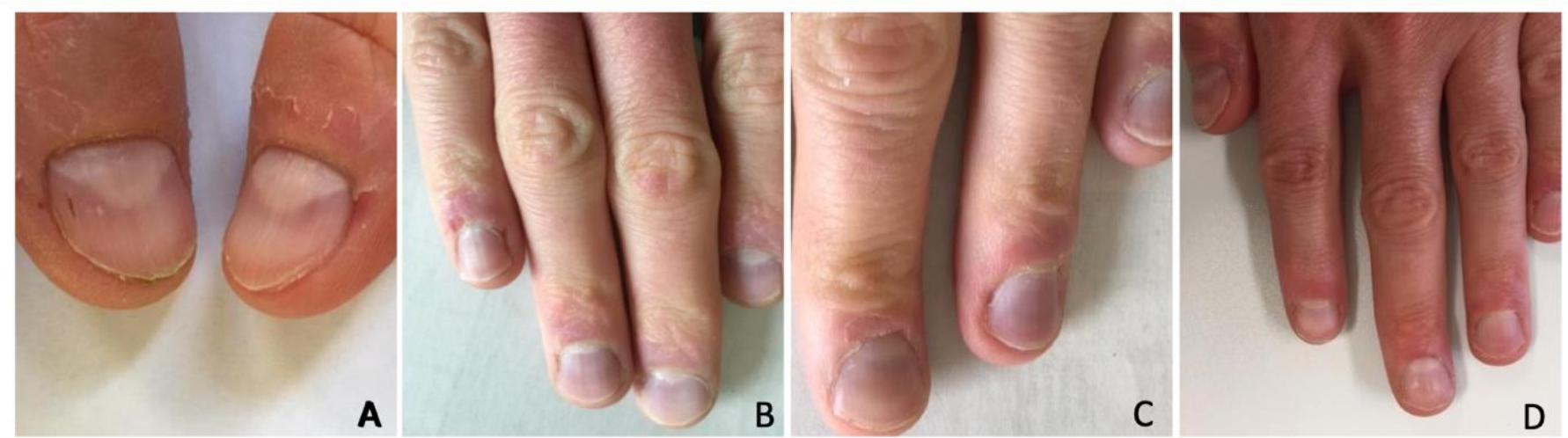

Figure 1. Thumbnail's condition (Source: Author's documentation)

Fig 1A: Thumbnails at baseline visit. Splinter hemorrhage within the nail plate of the right thumb is observed.

Fig 1B: One month after baseline visit, some improvement was seen.

Fig 1C: Four months after baseline visit, the redness around the cuticles was fading, the nails had grown a little longer and the patient was now able to clip them.

Fig 1D: Six months after baseline visit. The nail plate was smoother, but the edges had a bitten appearance.

\section{DISCUSS}

Onychophagia is an underestimated problem, which not only causes social problems and has a negative impact on quality of life but in addition can lead to inflammatory processes like gingivitis and paronychia., 2,7 The typical triggers for biting the nails are boredom, stress, or tenseness. ${ }^{8}$ There are several therapeutic approaches available for treating onychophagia, for instance a pharmacological approach with systemic $\mathrm{N}$ acetylcysteine $^{9}$ or mechanical remedies like wristbands. ${ }^{10}$ Habit reversal, first introduced in 1973, is another approach helping to get aware of the habit and transfer it to another harmless action by a competing response, which has been reported superior compared to physical remedies like bitter tasting enamel, and it has not always been proven successful even in a longer follow-up period. ${ }^{11,12,13,14}$
Our patient reported habit reversal provided a short-lasting reduction in decades of onychophagia. Habit reversal is suggested as a mean of helping patients suffering from onychophagia to get aware about the compulsion, biting and destroying of the nails. If it is beneficial for a longer period is doubtful. Lack of long-term effect may be due to low adherence or insufficient support for the patients. Despite the patient resumed nail-biting, he experienced relief, improved QOL and the nails looked better than six months before he started clipping the nails instead of biting them.

Although there seems to be differing success of habit reversal for longer lasting periods ${ }^{12,13,14}$ it is a promising way to establish self-reliance over the bothering habit. 


\section{CONCLUSION}

To maintain treatment compliance and adherence, the establishment of nail-biting clinics, run by a multidisciplinary team (consisting of dermatologists, psychiatrists, and psychologists) who ensure regular follow-ups, social support and patient compliance is monitored could be an option to achieve satisfactory therapy goals. Habit reversal yet needs to be tested in a superiority setting randomized controlled trial using validated scores for nail symptoms, where disease severity of the nails requisite to be assessed by a blinded investigator.

\section{REFERENCES}

1. Pacan P, Reich A, Grzesiak M, Szepietowski JC. Onychophagia is associated with impairment of quality of life. Acta dermato-venereologica. 2014;94(6):703-706.

2. Halteh P, Scher RK, Lipner SR. Onychophagia: A nailbiting conundrum for physicians. J Dermatolog Treat. 2017;28(2):166-172.

3. Miltenberger RG, Fuqua RW, Woods DW. Applying behavior analysis to clinical problems: review and analysis of habit reversal. J Appl Behav Anal. 1998;31(3):447-69.

4. Woods DW, Miltenberger RG. Habit reversal: a review of applications and variations. J Behav Ther Exp Psychiatry. 1995;26(2):123-31.

5. Woods D, Miltenberger R. A Review of Habit Reversal with Childhood Habit Disorders. Education and Treatment of Children. 1996;19:197-214.

6. Zachariae R, Zachariae C, Ibsen H, Mortensen JT, Wulf HC. Dermatology life quality index: data from Danish inpatients and outpatients. Acta Derm Venereol 2000;80:272-6.

7. Bohne A, Keuthen N, Wilhelm S. Pathologic hairpulling, skin picking, and nail biting. Ann Clin Psychiatry. 2005;17(4):227-32.

8. Ghanizadeh A, Bazrafshan A, Firoozabadi A, Dehbozorgi G. Habit Reversal versus Object Manipulation Training for Treating Nail Biting: A Randomized Controlled Clinical Trial. Iran J Psychiatry. 2013;8(2):61-7.

9. Ghanizadeh A, Derakhshan N, Berk M. N-acetylcysteine versus placebo for treating nail biting, a double blind randomized placebo controlled clinical trial. Antiinflamm Antiallergy Agents Med Chem. 2013;12(3):223-8.

10. Koritzky G, Yechiam E. On the value of nonremovable reminders for behavior modification: an application to nail-biting (onychophagia). Behav Modif. 2011;35(6):511-30.

11. Azrin NH, Nunn RG. Habit-reversal: a method of eliminating nervous habits and tics. Behav Res Ther. 1973;11(4):619-28.

12. Silber KP, Haynes CE. Treating nailbiting: a comparative analysis of mild aversion and competing response therapies. Behav Res Ther. 1992;30(1):15-22.

13. Allen KW. Chronic nailbiting: a controlled comparison of competing response and mild aversion treatments. Behav Res Ther. 1996;34(3):269-72.

14. Twohig MP, Woods DW, Marcks BA, Teng EJ. Evaluating the efficacy of habit reversal: comparison with a placebo control. J Clin Psychiatry. 2003 Jan;64(1):40-8. 